\title{
Application of anti-cancer nano drugs particles (ACNDP) to NMR characterization of viral gum cancer cell membrane DNA/RNA interactions for extracting DNA/ RNA dynamics information from overlapped NMR signals using relaxation dispersion difference NMR spectroscopy
}

\author{
Alireza Heidari ${ }^{1,2 *}$ and Ricardo Gobato ${ }^{3}$ \\ ${ }^{1}$ Faculty of Chemistry, California South University, 14731 Comet St. Irvine, CA 92604, USA \\ ${ }^{2}$ American International Standards Institute, Irvine, CA 3800, USA \\ ${ }^{3}$ Green Land Landscaping and Gardening, Seedling Growth Laboratory, 86130-000, Parana, Brazil
}

\begin{abstract}
In the current investigation, application of anti-cancer Nano drugs particles (ACNDP) to NMR characterization of viral gum cancer cell membrane DNA/RNA interactions for extracting DNA/RNA dynamics information from overlapped NMR signals using relaxation dispersion difference NMR spectroscopy are studied. NMR spectroscopy can also give an objective and reliable decision about malignancy and early malignant stages of anti-cancer Nano drugs particles (ACNDP) to NMR characterization of viral gum cancer cell membrane DNA/RNA interactions for extracting DNA/RNA dynamics information from overlapped NMR signals using relaxation dispersion difference NMR spectroscopy. This technique could help medical professionals in assessing with a clinically relevant specificity and sensitivity the location for most representative biopsies.
\end{abstract}

\section{Introduction}

To address the progress of the companies that are developing/ have developed commercial anti-cancer Nano drugs particles (ACNDP) to NMR characterization of viral gum cancer cell membrane DNA/ RNA interactions for extracting DNA/RNA dynamics information from overlapped NMR signals using relaxation dispersion difference NMR spectroscopy oncological applications towards implementation in the clinics, we have contacted leading companies in anti-cancer Nano drugs particles (ACNDP) to NMR characterization of viral gum cancer cell membrane DNA/RNA interactions for extracting DNA/RNA dynamics information from overlapped NMR signals using relaxation dispersion difference NMR spectroscopy to collect information [1-10].

\section{Results and discussion}

Prior to the development of technological tools aiming to improve diagnosis and/or treatment of gum cancer, it is important to define the actual clinical needs, because various clinical problems have different needs and solutions. Currently, two main oncological clinical needs, which could be fulfilled by application of anti-cancer Nano drugs particles (ACNDP) to NMR characterization of viral gum cancer cell membrane DNA/RNA interactions for extracting DNA/RNA dynamics information from overlapped NMR signals using relaxation dispersion difference NMR spectroscopy, have been identified: (A) diagnostic tools for biopsy guidance for early diagnosis of (pre-) malignant, and (B) tools for surgery guidance, which can be used for intra-operative assessment of resection margins to achieve adequate tumor resection (Figure 1).

\section{Conclusion}

Anti-cancer Nano drugs particles (ACNDP) to NMR characterization of viral gum cancer cell membrane DNA/RNA interactions for extracting DNA/RNA dynamics information from overlapped NMR signals using relaxation dispersion difference NMR spectroscopy has been explored for oncological applications in numerous studies, employing various types of measurement systems, and targeting various types of gum cancers. This section also provides a review of the use of anti-cancer Nano drugs particles (ACNDP) to NMR characterization of viral gum cancer cell membrane DNA/RNA interactions for extracting DNA/RNA dynamics information from overlapped NMR signals using relaxation dispersion difference NMR

${ }^{\star}$ Correspondence to: Alireza Heidari, Faculty of Chemistry, California South University, 14731 Comet St. Irvine, CA 92604; American International Standards Institute, Irvine, CA 3800, USA, E-mail: Scholar.Researcher.Scientist@gmail. com; Alireza.Heidari@calsu.us; Central@aisi-usa.org

Key words: anti-cancer nano drugs particles (ACNDP), NMR characterization, gum cancer, cell membrane, DNA/RNA interactions, dynamics, overlapped NMR signals, relaxation dispersion difference, NMR spectroscopy

Received: October 13, 2020; Accepted: November 09, 2020, Published: November 13, 2020 

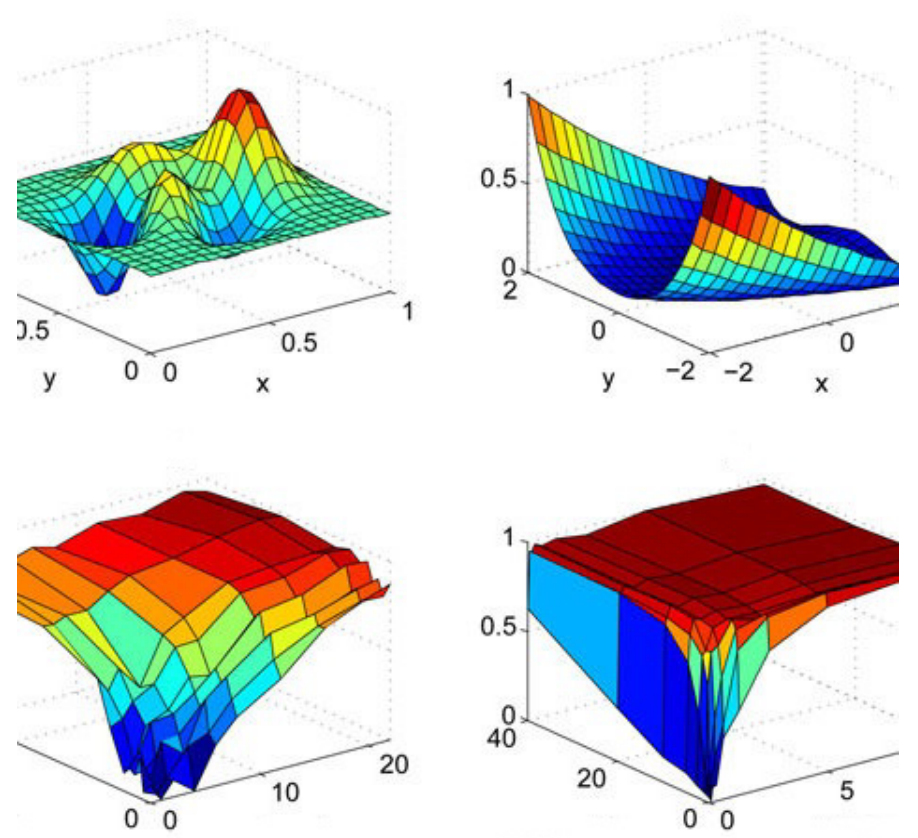

Figure 1. Anti-cancer Nano drugs particles (ACNDP) to NMR characterization of viral gum cancer cell membrane DNA/RNA interactions for extracting DNA/RNA dynamics information from overlapped NMR signals using relaxation dispersion difference NMR spectroscopy

spectroscopy ex vivo and in vivo for early diagnosis, biopsy guidance and surgery guidance of different types of gum cancer. Based on the search terms, 42 research papers on oncological applications of anti-cancer Nano drugs particles (ACNDP) to NMR characterization of viral gum cancer cell membrane DNA/RNA interactions for extracting DNA/RNA dynamics information from overlapped NMR signals using relaxation dispersion difference NMR spectroscopy were included.

\section{Acknowledgments}

This study was supported by the Cancer Research Institute (CRI) Project of Scientific Instrument and Equipment Development, the National Natural Science Foundation of the United Sates, the International Joint BioSpectroscopy Core Research Laboratory Program supported by the California South University (CSU), and the Key project supported by the American International Standards Institute (AISI), Irvine, California,USA.

\section{References}

1. Heidari A, Brown C (2015) Study of composition and morphology of cadmium oxide (CdO) nanoparticles for eliminating cancer cells. J Nanomed Res 2(5): 20.

2. Heidari A, Brown C (2015) Study of surface morphological, phytochemical and structural characteristics of rhodium (III) oxide $\left(\mathrm{Rh}_{2} \mathrm{O}_{3}\right)$ nanoparticles. International Journal of Pharmacology, Phytochemistry and Ethnomedicine 1(1): 15-19.

3. Heidari A (2016) An experimental biospectroscopic study on seminal plasma in determination of semen quality for evaluation of male infertility. Int $J$ Adv Technol 7: e007.

4. Heidari A (2016) Extraction and preconcentration of N-Tolyl-Sulfonyl-PhosphoramidSaeure-Dichlorid as an anti-cancer drug from plants: a pharmacognosy study. $J$ Pharmacogn Nat Prod 2: e103.

5. Heidari A (2016) A thermodynamic study on hydration and dehydration of DNA and RNA-Amphiphile Complexes. J Bioeng Biomed Sci S: 006.

6. Heidari A (2016) Computational studies on molecular structures and carbonyl and ketene groups' effects of singlet and triplet energies of Azidoketene $\mathrm{O}=\mathrm{C}=\mathrm{CH}-\mathrm{NNN}$ and Isocyanatoketene $\mathrm{O}=\mathrm{C}=\mathrm{CH}-\mathrm{N}=\mathrm{C}=\mathrm{O} . J$ Appl Computat Math 5: e142.

7. Heidari A (2016) Study of irradiations to enhance the induces the dissociation of hydrogen bonds between peptide chains and transition from helix structure to random coil structure using ATR-FTIR, Raman and ${ }^{~}$ HNMR Spectroscopies. J Biomol Res Ther 5: e146.

8. Heidari A (2016) Future prospects of point fluorescence spectroscopy, fluorescence imaging and fluorescence endoscopy in photodynamic therapy (PDT) for cancer cells. J Bioanal Biomed 8: e135.

9. Heidari A (2016) A bio-spectroscopic study of DNA density and color role as determining factor for absorbed irradiation in cancer cells. Adv Cancer Prev 1: e102.

10. Heidari A (2016) Manufacturing process of solar cells using cadmium oxide (CdO) and rhodium (III) Oxide $\left(\mathrm{Rh}_{2} \mathrm{O}_{3}\right)$ nanoparticles. J Biotechnol Biomater 6: e125.

Copyright: (C2020 Heidari A. This is an open-access article distributed under the terms of the Creative Commons Attribution License, which permits unrestricted use, distribution, and reproduction in any medium, provided the original author and source are credited. 